At the maximal exercise point in tests on patients taking the betablocker plus nitrate the systolic blood pressure was significantly lower and the heart rate slightly higher than in those taking the beta-blocker alone. Consequently the product (heart rate $\times$ systolic blood pressure) was also lower (15 820 compared with 17440 ), implying a reduction in myocardial work during the nitrate tests. In no patient was maximal exercise capacity diminished by the nitrate, while in seven out of 14 the increase was greater than $50 \%$.

\section{Discussion}

Nitrates act in angina by reducing both left ventricular preload (venous pressure) and after-load (blood pressure), both of which are determinants of myocardial work. The effect is that both diastolic pressure and volume as well as wall tension in the left ventricle are reduced, thereby diminishing myocardial oxygen consumption. ${ }^{5}$ Further benefits are increased coronary blood flow to the ischaemic myocardium ${ }^{9}$ and improved contraction of dyskinetic area in the left ventricle. ${ }^{6}$

Numerous studies have shown the value of beta-receptor blocking agents in increasing exercise tolerance and reducing anginal attacks. ${ }^{1-3}$ In contrast to nitrates, these drugs act by reducing the sensitivity of the myocardium to catecholamines during exercise and emotion, thereby reducing both the resting and exercise heart rate. They also reduce myocardial contractility and these two factors lower myocardial oxygen requirement. ${ }^{4}$

These effects are counteracted by an increase in left ventricular end-diastolic pressure and wall tension, and, even though overall cardiac performance is usually improved in anginal subjects, not all patients derive relief from beta-blockade -even when the dose is adjusted to reduce the peak exercise as well as the resting heart rate. ${ }^{10}$

Few studies have tested the possible synergestic effect of betablockers and nitrates. Russek ${ }^{11}$ reported increased exercise tolerance after propranolol and isosorbide, but this was not confirmed by Aronow, ${ }^{12}$ although timing of his exercise tests after nitrate administration, may have produced the results. Weiner ${ }^{13}$ in a detailed haemodynamic study reported improved exercise tolerance with reduction in left ventricular end-diastolic pressure in anginal subjects given intravenous propranolol plus sublingual glyceryl trinitrate, compared with a propranolol treated group.

In our study exercise tolerance was significantly increased by adding isosorbide to the patients already on beta-blockers, most of whom (eight out of the 10 studied) had either raised left ventricular end-diastolic pressure or dyskinetic areas of ventricle. Probably in them nitrates improved exercise tolerance by decreasing left ventricular work as a result of the fall in blood pressure and presumably left ventricular end-diastolic pressure.

The use of sublingual nitrates is often limited by their short action, and people still disagree about the role of rapid hepatic degradation of orally administered long-acting preparations in this effect. The effect of sublingual isosorbide dinitrate administered sublingually lasts for at least two hours ${ }^{14}{ }^{15}$ and when taken by patients with angina before exercise may be a useful addition to beta-blockade.

\section{References}

${ }^{1}$ Zeft, H J, Patterson, S, and Orgain, E S, Archives of Internal Medicine, $1969,124,578$

2 Gillam, P M S, and Prichard, B N C, British Medical Fournal, 1965, 2, 337.

${ }^{3}$ Keelan, P, British Medical Fournal, 1965, 1, 897.

4 Coltart, D J, et al, British Heart fournal, 1975, 37, 357.

${ }^{5}$ Kasparian, H, et al, American Heart fournal, 1975, 90, 68.

${ }^{6}$ McAnulty, J H, et al, Circulation, 1975, 51, 140.

7 Reddy, S P, et al, American Heart fournal, 1975, 90, 479.

${ }^{8}$ Bruce, R A, Kusumi, F, and Hosmer, D, American Heart fournal, 1973, $85,546$.

9 Becker, L C, Fortinn, W J, and Pitt, B, Circulation Research, 1971, 28, 263

${ }_{10}$ Jackson, G, Atkinson, L, and Oram, S, British Medical fournal, 1975, 3, 616 .

${ }_{11}$ Russek, H I, American Fournal of the Medical Sciences, 1967, 254, 406.

12 Aronow, W S, and Kaplan, M A, New England fournal of Medicine, 1969, 280, 847 .

13 Wiener, L, Dwyer, E M, and Cox, J W, Circulation, 1969, 39, 623.

${ }^{14}$ Baxter, R H, Tait, C M, and McGuinness, J B, British Heart fournal, 1977. In press.

15 Willis, W H, et al, Chest, 1976, 69, 15.

\title{
Amoxycillin and co-trimoxazole in presumed viral respiratory infections of childhood: placebo-controlled trial
}

\author{
BRENT TAYLOR, G D ABBOTT, M MCK KERR, D M FERGUSSON
}

British Medical fournal, 1977, 2, 552-554

\section{Summary}

A double-blind randomised controlled trial of amoxycillin, co-trimoxazole, and placebo was conducted on 197 children presenting with presumed viral respiratory infections. Routine throat swabs were taken to exclude streptococcal disease. The three disease categories studied-nasopharyngitis, pharyngotonsillitis, and bronchitis (including laryngotracheobronchitis)-showed a

Department of Paediatrics, The Christchurch Clinical School, Christchurch Hospital, Christchurch, New Zealand

BRENT TAYLOR, MRCP, MRACP, senior lecturer

G D ABBOTT, MD, FRACP, senior lecturer

D M FERGUSSON, BA, research officer

St Albans Medical Centre, Christchurch, New Zealand

M MCK KERR, DOBST, MNZCGP, general practitioner generally similar pattern of resolution irrespective of treatment.

Nevertheless, seven out of 66 children receiving placebo were withdrawn from the trial with unremitting symptoms or complications thought to require antimicrobial treatment. Only two of 56 children receiving amoxycillin and none of 75 receiving co-trimoxazole were withdrawn. Three other children receiving amoxycillin and three receiving placebo were seen during the trial but further treatment was not thought to be necessary. Thus the return consultation rate in children receiving placebo therapy was $15 \%$ compared with $4 \%$ for those receiving antimicrobial treatment. Antimicrobial treatment was associated with less nasal discharge on the eighth day of treatment. Placebo treatment allowed an earlier return to normal activity. There was a high incidence of possible side effects on all regimens including placebo.

It is concluded that the benefits of antimicrobial treatment in presumed viral respiratory infections are marginal, and they should not be routinely prescribed for these conditions. 


\section{Introduction}

Most childhood respiratory infections are caused by viruses. Nevertheless, antimicrobial agents are often prescribed for these infections despite considerable evidence that these drugs are ineffective and often harmful. ${ }^{2} 3$ We report the results of a double-blind placebo controlled trial to assess the effects of amoxycillin (Amoxil) and co-trimoxazole (trimethoprim $40 \mathrm{mg}$, sulphamethoxazole $200 \mathrm{mg}$; Bactrim, Roche) on presumed viral respiratory infections in childhood. We examined the effects of these drugs on the rate of remission of specific symptoms; the rate of resumption of general well-being; and the incidence of undesirable side effects or complications.

\section{Subjects and methods}

Subjects for the experiment were all children aged 2 to 10 years with presumed viral infections attending a five-doctor suburban group practice during a 10 -week period in late winter. Children clinically diagnosed as suffering from otitis media, or pneumonia, or those with group A $\beta$-haemolytic streptococci detected in throat swabs were excluded. Five other children were excluded because of parental refusal to participate. The total number of participants was 197 .

Subjects were classified by the general practitioner on presentation into the following three diagnostic categories.

Nasopharyngitis-Nasal discharge, clear or purulent, with or without red throat and fever (42 children).

Pharyngotonsillitis-Red throat or tonsils with or without exudate, cervical adenopathy, or fever (71 children).

Bronchitis or laryngotracheobronchitis (croup)-Productive-sounding cough with auscultatory evidence of more extensive peripheral airways disease such as rales or rhonchi (bronchitis); brassy cough with hoarseness or stridor (croup). Each with or without nasal discharge, red throat, or fever ( 84 children).

Subjects were assigned randomly on a double-blind basis to three treatment groups-placebo; amoxycillin $(125 \mathrm{mg} / 5 \mathrm{ml})$; co-trimoxazole (sulphamethoxazole $200 \mathrm{mg}$ and trimethoprim $40 \mathrm{mg} / 5 \mathrm{ml}$ ). Placebo or antimicrobial was given approximately eight-hourly, at least half an hour before food, for five days. The parents were asked to bring the child back for assessment the same day of the following week, and to contact the medical centre between times if concerned about the child's condition.

\section{DOCUMENTATION}

Clinical recordings-A standard precoded diary was issued to be completed for each of the eight days of the trial. It described: specific symptoms (clear or purulent nasal discharge, sore throat, cough, wheeze, and fever); general functioning (the level of the child's appetite and activity); side effects or complications (vomiting, diarrhoea, rash, or painful ears). The diary was checked for completion on the eighth day. At the same time the amount of medicine remaining was measured as a guide to patient compliance.

Failures-If bothersome new symptoms developed or the child's condition continued to cause the parent concern the child was seen again. If the examining doctor considered that antimicrobial treatment of known effect was more appropriate the child was withdrawn from the study and the reasons recorded.

Bacteriology-Throat swabs were taken on day one and day eight, and immediately placed into Stuart's transport medium. They were subsequently cultured on blood agar within six to 18 hours of collection, and any organisms grown were identified by standard techniques.

\section{Results}

One hundred and eighty-eight children completed the study; nine children failed to complete the trial. These last children returned to the doctor with persisting symptoms or complications such as otitis media during the trial, and were prescribed an antimicrobial agent. Although this incidence of failures was small ( $5 \%$ ), seven of the nine children came from the placebo group (four with initial diagnosis of pharyngotonsillitis and three with bronchitis). This distribution of failures was unlikely to be the result of chance variation $(P<0.01$; binomial theorem). Six other children (three receiving amoxycillin, three receiving placebo) were seen again during the trial, but were considered not to require further medication (table I). There was no apparent failure to take the medicine. In no case was there more than one quarter of the drug left, and in most instances the bottle was empty. No cases were lost to follow-up.

TABLE I-Numbers of children in placebo and antimicrobial groups who returned to the medical centre during the trial because of persisting symptoms or complications, and who were withdrawn or continued

\begin{tabular}{c|c|c|c}
\hline & $\begin{array}{c}\text { Amoxycillin } \\
(\mathrm{n}=56)\end{array}$ & $\begin{array}{c}\text { Co-trimoxazole } \\
(\mathrm{n}=75)\end{array}$ & $\begin{array}{c}\text { Placebo } \\
(\mathrm{n}=66)\end{array}$ \\
\hline Withdrawn because of: & 1 & & 4 \\
Otitis media & 1 & 3 \\
Other complications* & 3 & 3 \\
Completed trial† & $5(9)$ & & $30(15)$ \\
Total (\% of group) & & 10 \\
\end{tabular}

*Three cases of wheezy bronchitis; one of persisting sore throat.

$\dagger$ Two cases of persistent cough; one of persisting sore throat; one of suspected thrush; one of suspected otitis media (not clinically); one of persisting wheezing.

\section{ANALYSIS OF DATA}

The experiment (excluding the nine failures withdrawn from the trial) was analysed as $3 \times 3 \times 4$ multivariate analysis of variance (MANOVA) design, ${ }^{4}$ in which four criteria for improvement were contrasted over the three treatment categories and the three diagnoses. The four criteria used in the analysis were: the number of specific symptoms the child had on day 4 of the trial; the number of symptoms on day 8; and the days until the return of normal activity and appetite. A child was considered as having returned to normal on the first of at least two consecutive days on which his parent recorded normal activity or appetite.

The analysis showed, firstly, that there was a significant difference between the three treatments in the rate of recovery as assessed by the criteria for improvement when these criteria were analysed simultaneously $(P<0.002)$; secondly, that there was no significant difference in the rate of recovery between the three diagnostic conditions; and, thirdly, that no treatment had a significantly different effect from the other treatments on any of the disease categories studied (treatment-diagnosis interaction). (Details of the analysis and results are available from the authors on request.)

As there was no treatment-diagnosis interaction we examined the only significant result of the multivariate analysis of variance-the effect of the different treatments on symptoms-by pooling the data over the three diagnostic categories. Table II shows for each treatment group the mean number of respiratory symptoms per day, the proportion of children per day who had not returned to normal activity, and the proportion of children per day who had not resumed normal appetite.

Univariate analysis of variance on the four criteria for improvement carried out on the pooled data showed that although there were no significant differences between the treatments with respect to specific symptoms at day four, the differences were significant by day eight $(P<0.02)$. The mean number of days to resumption of normal activity was also significantly different for the three treatment groups $(P<0.05)$.

Table III shows the distribution of specific symptoms among the three treatment groups at day eight of the trial. The main reason for the superiority of the groups treated with antimicrobials is that they had a lower incidence of nasal discharge.

Side effects and complications-Table IV shows the number of children in each treatment group who suffered from the presumed side effects of vomiting, diarrhoea, and rash. The incidence of side effects was randomly distributed across the treatment groups $(P>0.05)$. Thirteen children each in the amoxycillin and cotrimoxazole groups and eight in the placebo group had the symptom of painful ears recorded in their diaries. Five more children developed otitis media during the study and were seen again (table I). Table I also gives details of the other complications needing medical review.

\section{Discussion}

There were two principal unexpected findings in this study: firstly, the comparatively high incidence of treatment failure and return consultation rate among children receiving placebo treatment, and, secondly, the effects of antimicrobials compared with placebo on symptoms, which were beneficial on the symptom of nasal discharge but detrimental in terms of rapidity of return to normal activity. 
TABLE II-Mean number of respiratory symptoms, numbers of children who had not returned to normal activity, and numbers of children who had not resumed normal appetite in placebo $(n=59)$, co-trimoxazole $(n=75)$, and amoxycillin $(n=54)$ treatment groups over eight days

\begin{tabular}{|c|c|c|c|c|c|c|c|c|c|}
\hline \multirow{2}{*}{ Day } & \multicolumn{3}{|c|}{ Symptoms (possible $=6$ ) } & \multicolumn{3}{|c|}{ Appetite $\left({ }^{\circ} 0\right)$} & \multicolumn{3}{|c|}{ Activity $\left({ }^{\prime}{ }_{0}\right)$} \\
\hline & Placebo & Co-trimoxazole & Amoxycillin & Placebo & Co-trimoxazole & Amoxycillin & Placebo & Co-trimoxazole & Amoxycillin \\
\hline $\begin{array}{l}1 \\
2 \\
3 \\
4 \\
5 \\
6 \\
7 \\
8\end{array}$ & $\begin{array}{l}3.05 \\
2.78 \\
2.36 \\
1.95 \\
1.69 \\
1.46 \\
1.47 \\
1.20\end{array}$ & $\begin{array}{l}3.08 \\
2.51 \\
2.04 \\
1.68 \\
1.45 \\
1.24 \\
0.92 \\
0.79\end{array}$ & $\begin{array}{l}2.98 \\
2.35 \\
1.81 \\
1.56 \\
1.26 \\
0.92 \\
0.70 \\
0.54\end{array}$ & $\begin{array}{r}42(71) \\
37(63) \\
30(51) \\
20(34) \\
15(25) \\
12(20) \\
11(19) \\
8(14)\end{array}$ & $\begin{array}{l}57(76) \\
49(65) \\
34(45) \\
26(35) \\
18(24) \\
14(19) \\
11(15) \\
8(11)\end{array}$ & $\begin{array}{l}40(74) \\
35(65) \\
27(50) \\
17(31) \\
16(30) \\
12(22) \\
11(20) \\
9(17)\end{array}$ & $\begin{array}{c}42(71) \\
36(61) \\
20(34) \\
13(22) \\
7(12) \\
3(5) \\
3(5) \\
2(3)\end{array}$ & $\begin{array}{c}51(68) \\
39(52) \\
24(32) \\
16(21) \\
11(15) \\
9(12) \\
6(8) \\
4(5)\end{array}$ & $\begin{aligned} & 41(76) \\
& 36(67) \\
& 31(57) \\
& 16(30) \\
& 12(22) \\
& 10(19) \\
& 6(11) \\
& 6(11)\end{aligned}$ \\
\hline
\end{tabular}

TABLE III-Number (\%) of children in the three treatment groups with symptoms remaining at day eight

\begin{tabular}{l|c|c|c}
\hline \multicolumn{1}{c|}{ Symptom } & $\begin{array}{c}\text { Amoxycillin } \\
(\mathbf{n}=54)\end{array}$ & $\begin{array}{c}\text { Co-trimoxazole } \\
(\mathbf{n}=75)\end{array}$ & $\begin{array}{c}\text { Placebo } \\
(\mathbf{n}=59)\end{array}$ \\
\hline Runny nose (clear) & $8(14 \cdot 81)$ & $21(28 \cdot 38)$ & $22(37 \cdot 29)$ \\
Runny nose (purulent) & $3(5 \cdot 56)$ & $3(4 \cdot 05)$ & $9(15 \cdot 25)$ \\
Sore throat & $3(5 \cdot 56)$ & $3(4 \cdot 05)$ & $3(5 \cdot 08)$ \\
Cough & $22(40 \cdot 74)$ & $29(39 \cdot 19)$ & $29(49 \cdot 15)$ \\
Wheezy chest & $1(1 \cdot 85)$ & $5(6 \cdot 76)$ & $6(10 \cdot 17)$ \\
Hot and feverish & & $1(1 \cdot 35)$ & $1(1 \cdot 69)$ \\
\hline
\end{tabular}

TABLE IV-Numbers of children in the three treatment groups with possible side effects

\begin{tabular}{l|c|c|c|c}
\hline \multicolumn{1}{c|}{ Side effect } & $\begin{array}{c}\text { Amoxycillin } \\
(\mathbf{n}=54)\end{array}$ & $\begin{array}{c}\text { Co-trimoxazole } \\
(\mathrm{n}=\mathbf{7 5})\end{array}$ & $\begin{array}{c}\text { Placebo } \\
(\mathrm{n}=59)\end{array}$ & Total $\left({ }^{\circ}{ }_{0}\right)+$ \\
\hline Diarrhoea & 8 & 10 & 6 & $24(12 \cdot 8)$ \\
Rash & 2 & 9 & 6 & $17(9 \cdot 0)$ \\
Vomiting & 5 & 8 & 7 & $20(10 \cdot 6)$ \\
Total number & $8(14 \cdot 8)$ & $18(24 \cdot 0)$ & $11(18 \cdot 6)$ & $37(19 \cdot 7)$ \\
$\begin{array}{l}\text { (\%) with } \\
\text { side effects* }\end{array}$ & & & & \\
\hline
\end{tabular}

* Some children had more than one side effect.

†Expressed as percentage of total number of children $(n=188)$ remaining in study.

Most previous studies ${ }^{2}{ }^{3}$ had led us confidently to expect that there would be no differences in the effects of antimicrobials compared with placebo on the course of recovery from viral respiratory infections (provided pharyngotonsillitis caused by group A $\beta$-haemolytic streptococci was excluded), but that there might be a higher incidence of side effects in children receiving antimicrobials. Of the 15 children requiring further medical attention during the trial, 10, however, were receiving placebo. Seven of these were considered by the examining doctor to require antimicrobial treatment-four developed clinical otitis media and three had persisting or worsening symptoms (table I). Although a single throat swab, as used in this study, is not a completely reliable method for diagnosing sore throat due to streptococcal infection, undetected group A $\beta$-haemolytic streptococcal infection seems an unlikely explanation for this failure rate, as only one of these children had a persisting sore throat. We have no clear explanation for this failure rate in those treated with placebo. Nevertheless, among those for whom placebo treatment failed were four patients with otitis media - so the problem may have been the difficulty of early recognition of clinical events with a bacterial rather than a viral cause.

The course of recovery of the groups treated with antimicrobials differed from the placebo-treated group in two contrasting ways. After day two those receiving placebo had more specific symptoms. The apparent superiority of antimicrobials by day eight was mainly because children in this group lost their nasal discharge earlier (table III). Both antimicrobials seemed to suppress purulent discharge. Amoxycillin appeared to suppress clear nasal discharge as well. This result is paralleled by a recent study of adults presenting with cough and sputum, in which treatment with doxycycline resulted in a lower incidence of clear nasal discharge than did placebo. ${ }^{5}$

Faster relief from specific symptoms for those receiving antimicrobials, however, was not associated with a faster rate of return to normal appetite and activity; the placebo group were superior in this respect. This difference did not seem to be the result of side effects from antimicrobial treatment as there were no significant differences between the groups in the incidence of these effects. The incidence of possible side effects was high (table IV). Diarrhoea, vomiting, and rashes are often blamed on antimicrobial treatment, but they occurred as frequently with placebo treatment, suggesting that such symptoms commonly accompany viral respiratory illnesses.

The discrepancy between our results and those of previous workers could be explained in at least two ways. It could be suggested that the results emerge from some bias or failure in the experimental design-for example, failure of the doubleblind design, the effects of missing cases. This is unlikely, since our data shows both positive and negative effects of antimicrobials. Moreover, any bias in the design probably would have operated to favour consistently either the antimicrobial or placebo groups. Our follow-up was complete. Furthermore, our study differs from previous research in at least two ways. First, we used a precoded diary to record symptoms, which permitted a continuous and standard measurement of the child's condition. Secondly, the method of analysis we used (MANOVA) allows several dependent variables to be assessed simultaneously. These features may have made the analysis more sensitive so that small, previously unnoticed differences could be detected.

Nevertheless, our findings have the same practical implications for children with presumed viral respiratory infection. Unless group A $\beta$-haemolytic streptococci are isolated from throat swabs, the routine prescription of antimicrobials should be resisted, as any benefit is marginal. A more rapid relief of symptoms, principally nasal discharge, is offset by a slower rate of return to normal health. Any slight benefit must be balanced against the cost of antimicrobials and the slight risk of sensitisation and other unwanted effects, particularly the problem of increasing drug resistance in the community. For many patients the usual course of antimicrobials (five to seven days) will also be insufficient to eradicate group A $\beta$-haemolytic streptococci. ${ }^{6}$ Withholding antimicrobials from patients will result in only a few of them returning for further treatment. The failure rate observed in this study would have resulted in an extra threetenths of a consultation per doctor per week if none of the children had been prescribed antimicrobial treatment. If identification of bacterial infection is improved, such failures might be further reduced.

We are very grateful to Doctors D R Dalley, D R Laing, $\mathrm{K}$ W Warden, and $P \mathrm{~J}$ Watt, and the practice nurses of the St Albans Medical Centre for their co-operation in this study; we also thank Mrs Jane Cameron, BSc, for help with the data processing and Miss Kay Read for secretarial help.

\section{References}

1 Gardner, P S, Archives of Disease in Childhood, 1968, 43, 629.

${ }^{2}$ Davis, S D, and Wedgwood, R J, American fournal of Diseases of Children, 1965, 109, 544.

3 Soyka, L F, et al, Pediatrics, 1975, 55, 552.

4 Tatsuoka, M M, Multivariate Analysis. New York, Wiley, 1971.

5 Stott, N C H, and West, R R, British Medical fournal, 1976, 2, 556.

${ }^{6}$ Garrod, L P, Lambert, H P, and O'Grady, F, Antibiotic and Chemotherapy, 4th edn. London, Churchill Livingstone, 1973.

(Accepted 5 fuly 1977) 